\title{
Cerâmicas omíadas do Garb Al-andalus: Resultados arqueológicos no Castelo Velho de Alcoutim e no Castelo das Relíquias (Alcoutim)
}

\author{
Helena Catarino *
}

\section{INTRODUÇÃO}

"Es de esperar que la Arqueología aporte nueva documentación, y que estas conclusiones aquí esbozadas en un plazo breve puedan ser confirmadas o reestructuradas de acuerdo con la información que nos ofrezcan los nuevos hallazgos e investigaciones suscitadas por este trabajo"

Rosselló-Bordoy, (1978: 156)

Deste modo terminou Rosselló a sua obra "Ensayo de Sistematización..." onde, pela primeira vez, houve uma preocupação de síntese sobre terminologias, tipologias e cronologias aplicadas a cerâmicas islâmicas, com bases nas escavações de Mallorca. Passaram 20 anos; mas este trabalho pioneiro continua a servir como base de estudo para todos nós. Rosselló tem sido um Mestre; aquele que, pela sua séria e atenta investigação, trouxe à Arqueologia Medieval do período islâmico uma nova dinâmica de trabalho, que marcou também os investigadores portugueses.

Mais recentemente, compilou e ordenou, com base em documentos (ROSSELLÓ BORDOY, 1991; 1994: 37-87), um conjunto de palavras árabes utilizadas para designar recipientes de uso quotidiano. Como o próprio diz: "el castellano y el catalán som suficientemente ricos en arabismos, como para buscar elementos extraños a nuestras lenguas y a la cultura material que motiva nuestras investigaciones" (ibid., 1991: II). Acrescentaria que, também no português, podemos encontrar um certo número de nomes de origem árabe para indicar recipientes domésticos.

Neste caso, optei por fazer coincidir, sempre que possível, a terminologia árabe com a castelhana e a portuguesa, para descrever um conjunto de cerâmicas encontradas durante as escavações do Castelo Velho de Alcoutim e do Castelo das Relíquias (CATARINO, 1988; 1989 : 296-305; 1994: 657-67I). Das I 6 formas abaixo indicadas estão ausentes, de momento, fragmentos de anafes (fogareiros).

$\bigcirc$ estudo das cerâmicas aqui apresentadas teve por base métodos descritivos e cronológicos já utilizados por outros investigadores, sobretudo Rosselló (1978), Bazzana (1979: 135-185, 1980: 57-95) e Zozaya ( 1080a: 265-296, 1980b: 3||$-3 \mid 5)$. As peças seleccionadas correspondem a duas fases de ocupação observadas nos referidos castelos: a primeira coincide com a edificação dos recintos amuralhados e das estruturas habitacionais mais antigas (níveis 6 e 5), do período emiral e transição para o califal; a segunda corresponde a reconstruções e, sobretudo, a reestruturações no ordenamento habitacional (nível 4), verificadas em pleno período califal e na transição para os reinos de taifa, época em que

* Assistente da Faculdade de Letras da Universidade de Coimbra e investigadora da UNIARQ. Instituto de Arqueología. Palacio de Sub-Ripas. 3000 Coimbra - Portugal 


\begin{tabular}{|c|c|c|}
\hline ARABE & CASTELHANO & PORTUGUES \\
\hline burma, qidr & marmita, olla & panela \\
\hline qas'a, tâyin, qasûla & cazuela & caçoila, sertã ou frigideira \\
\hline sahfa, tayfûr, gidar & ataifor & prato, tigela ou malga \\
\hline yafna e tass & jofaina e taza & escudela, taça \\
\hline radûma, kûz & redoma & peq. bilha, alcuza, galheta \\
\hline ibrîq & jarro, jarrito & jarro, jarrinho, púcaro ou pucarinho \\
\hline surayba, barrada & jarrita & jarrinha, pucarinha \\
\hline yarra, surba & jarra & cântaro, bilha, cantarinha, infusa \\
\hline jâbîya & tinaja & talha \\
\hline qulla & orza & pote \\
\hline libril, qasrîya, qadh & alcadafe, lebrillo & alguidar (de gidâr) \\
\hline gitâ, mugatta & tapadera & testo, tampa \\
\hline tabaq & disco & tampa plana \\
\hline qandîl, misbâh & candil & candeia \\
\hline qâdûs & arcaduz & alcatruz \\
\hline tannûr, farayen (de furayn) & (atanor), anafe & (atanor), fogareiro \\
\hline
\end{tabular}

estes castelos ainda estão habitados para, de seguida, entrarem num progressivo abandono (nível 3), queda de telhados (nível 2) e derrubes de paredes e muralhas (nível I).

\section{ESTUDO DAS CERAMICAS}

\section{I. Recipientes de uso culinário}

Entre os recipientes de cozinha predominam as panelas (ollas) e caçoilas ou sertãs (cazuelas). As panelas encontradas nos níveis da I a fase, algumas sem asa (Est. I. I), têm bordos boleados com inflexão externa (Est. I. I, 2 e 4) e, mais raramente, um sulco interno (est. I. 3), de modo a poder ajustar-se a uma tampa (tapadera). Os colos são curtos, em ligação para o bojo, ovóide, apresentando o típico perfil em S. Os fundos são planos, normalmente mais espessos e irregulares na ligação com a parte inferior do corpo. Apresentam, de um modo geral, uma só asa (Est. I. 2) e, mais raramente, duas (Est. I. 4), que partem sempre do bordo e terminam a meio do bojo. Os fabricos são grosseiros, a torno de rotação intermitente, obtendo-se paredes de espessura irregular, com vestígios dos dedos do oleiro, principalmente na superfície interna. As superfícies externas são levemente alisadas, sem decoração.
Têm paralelos em peças datadas de inícios do século VIII, por exemplo de Bovalar, Lérida (C.E.V.P.P., I99।: fig. 9. I a 3), por vezes com decoração incisa no ombro; do período emiral são as de Saragoça (GALVE IZQUIERDO, 1988: 248, FIG. 7. 20); e as recolhidas em Arcávica, Cuenca (ÁLVAREZ DELGADO, 1989: I I I, fig. 1. 23 e 25). São idênticas a exemplares de Badajoz (VALDÉS FERNANDEZ, 1985: 102, 119, fig. 7. 1-2), às do Cerro da Vila, Vilamoura, com traços de pintura no bojo (MATOS, 1991: 430, 439 n 0060), de Mesas do Castelinho, Almodôvar (FABIÃO et al, 1991: fig. 6.4 e fig. 7.2) e de Mértola (TORRES, 1987: I).

As da $2^{\text {a }}$ fase têm uma (Est. II. I) ou duas asas (Est. II. 2). São formas semelhantes às anteriores, com bordo boleado de inflexão externa, por vezes de perfil quase triangular e, raramente, com sulco interno para a tampa. $\bigcirc$ colo é ainda curto, mas também pode ser mais alongado (Est. II. 2); o corpo é ovóide ou globular e o fundo plano. As asas partem sempre do bordo e terminam no ombro ou na parte mais alta do bojo. Pertencem ainda a fabricos grosseiros mas, na maior parte, já apresentam fabrico a torno alto regular.

Têm também amplos paralelos, nomeadamente em Conimbriga (ALARCÃO, 1975: pl. XLVII, n 870), no Forum IV, datado do século $V$, e 
aproximam-se da forma A de Gutierrez Lloret (1988: 196-197, 216). As de fabrico a torno baixo (torneta), aparecem em contextos dos séculos VII e VIII, por exemplo em Begastri, la Alcudia e Fontcalent, integradas na forma M6.5 de Gutierrez Lloret (1996: 81, fig. 19, 82). São muito frequentes no sudeste de al-Andaluz (ACIÉN ALMANSA et al., 1995: 127, forma 423) e semelhantes às dos níveis inferiores de Bezmiliana (ACIÉN ALMANSA et al., 1989: 131 - 132, fig. 5. 4), da alcáçova de Badajoz (VALDÉS FERNANDEZ, 1985: 150, fig. 40), de Cercadilla, Córdova (FUERTES SANTOS et al., 1993: 773-774, 776, lám. I), de El Castillon (Montefrio, Granada), com algumas variantes no perfil do bordo (MOTOS GUIRAO, 1991: 36, fig. 4), e da área urbana de Múrcia (NAVARRO PALAZÓN, 1986: 143, n 302). Em Portugal, encontram-se, entre outros sítios, na alcáçova de Mértola (TORRES, 1987: 1) e em Mesas do Castelinho (GUERRA et al., 1993: 95, fig. I).

A série cazuela (sertã ou frigideira) caracteriza-se por paredes curvo-convexas, que terminam num fundo espesso, normalmente plano (Est. I. 6). Os bordos podem ser boleados, com inflexão externa, ou em aba oblíqua. As asas são grosseiras, verticais, de secção oval irregular, partem do bordo e terminam na parte baixa do corpo, quase junto do fundo. As pastas são heterogéneas, de fabricos manuais ou a torno baixo. As superfícies são alisadas ou com brunido em espatulado interno. Alguns exemplares, embora sem asas, pertenceriam a este grupo pois possuem restos de queimado aderente, devido à prolongada utilização ao fogo.

Têm paralelos em Conimbriga (sem asas), nas insulae do século V (ALARCÃO, 1975: pl. XXXII. 660) e são semelhantes às produzidas em Bayyana (Pechina), registadas no nível I (CASTILLO GALDEANO et al., 1993: , 80, 82, 83, Lám. III. 4-6) e no nível 2 (ibid.: 103, Lám. XIV. 5-7), assim como no forno emiral de Málaga (IÑIGUEZ SÁNCHEZ et al, 1993: Lám. 9. 7-8). Podem encontrar-se também em Navasangil, Ávila (LARRÉN IZQUIERDO, 1989: 6।, fig. 4. I I3), no pátio do poço-cisterna de Silves (GOMES et al., 1989: 294, nº 3) ou no Cerro da Vila, Vilamoura (MATOS, 1991: 453 nº 0047 e 0145 ). Uma com perfil idêntico, sem vestígios de asas, foi recolhida em Mesas do Castelinho (FABIÃO et al,, 1991: 319, fig. 8. 5).

\subsection{Recipientes de serviço de mesa}

Um conjunto de formas abertas e fechadas, utilizadas como serviço de mesa, podem incluirse nas séries ataifor (pratos, tigelas), redoma (pequena bilha, alcuza, galheta), jarrito (jarrinho, púcaro ou pucarinho) e jarrita (jarrinha, pucarinha).

A série ataifor está representada em peças não vidradas e vidradas. No primeiro grupo (Est. I. 5; Est. II. 5 e 6) indicam-se pratos sem pé anelar, umas vezes integrados no grupo ataifor, outras no grupo cazuela. Têm paredes curvoconvexas (Est. II. 5), ou quase rectilíneas divergentes (Est. II. 6), com amplo fundo plano; os bordos, com inflexão externa, podem ter perfil semi-circular ou em bisel. Exumaram-se em todos os níveis estratigráficos e alguns levaram engobe interno, de cor castanha avermelhada, e brunido em espatulado ou em rectícula.

Predominam também no período emiral e califal, continuando a circular nos inícios dos reinos de taifa, integradas no grupo I dos ataifores/jofainas, de Retuerce e Zozaya ( 199 I: fig. $3,1-7)$, com uma periodização que vai desde a fase paleo-andaluza (emiral) até à fase epi-califal, já do século Xl. Aproximam-se da forma M27.4. I de Gutierrez Lloret (1996: 93 e fig. 26), das exumadas na camada 8 do Castelo de Silves (GOMES, 1988: 188-189), na Rábita de Dunas de Guardamar, Alicante (AZUAR RUÍZ et al., 1989: 81, n० 43 e 44; II6, 9.I), em Bayyana (CASTILLO GALDEANO et al., 1993: 83, lám. III. I), em Málaga, Almeria (ACIÉN ALMANSA, 1986: 254, fig. 4. 4; ACIÉN ALMANSA et al., 1989: 126, fig.. I. I) e Jaén (CASTILLO ARMENTEROS, 1996: 194, fig. 2.3 e 4). Podem apresentar decoração pintada no interior e/ou no bordo, como as de Silves (GOMES, 1988: 187, Q3/C8-24) e de Mesas do Castelinho, Almodôvar (FABIÃO et al., |991: 319, fig. 8. 4).

Os ataifores de pé anelar, com superfícies vidradas, registaram-se exclusivamente os níveis arqueológicos da $2^{\text {a }}$ fase de ocupação e agrupamse nas decorações a verde e manganés e nos melados com decoração a óxido de manganés.

As decoradas a verde e manganés integram-se, conforme as dimensões, nas séries 
ataifor (tigelas, malgas, Est. II. 9, II e |2) e jofaina (taças mais pequenas, Est. II. 10). Exumaram-se no Castelo Velho de Alcoutim e apresentam decorações típicas dos séculos $X / X I$, sobretudo em flor e bolbo de lótus (Est. II. 9 e 10) ou em bandas e meandros, estas recolhidas em escassos fragmentos, nos níveis de derrubes (Est. II. II e 12). Os bordos podem ser adelgaçantes ou espessados externamente, com perfil semicircular e, mais raramente, triangular. O corpo, de paredes curvas, mais ou menos acentuadas, pode ter um ressalto na ligação com o pé anelar, pequeno e de secção quadrangular. A decoração é feita, maioritariamente, sobre engobe branco, e as superfícies vidradas de tonalidades transparentes, meladas claras, esverdeadas e esbranquiçadas. Um único exemplar possui superfície externa com vidrado branco leitoso opaco. Os fabricos são sempre de boa qualidade com pastas creme, esbranquiçadas, amareladas, rosadas ou acinzentadas claras.

Como se pode observar no mapa apresentado por Retuerce e Zozaya (1986: I02, Mapa 7) têm ampla difusão em Al-Andaluz. Em Portugal, aparecem sempre em contextos cronológicos dos séculos $X|X|$, excepto as da camada 8 de Silves, consideradas importações do século VIII (GOMES, 1988: 181-183; 1991a: 21-26, 1995: 20 fig. I). A Norte do Tejo podem encontrar-se em Santarém (informações de Ana Arruda), no Castelo dos Mouros, Sintra (COELHO, 1996: Est. IV. 6, 7 e 8) e no Castelo de Povos, Vila Franca de Xira (informações de Cristina Calais). Estão bem representadas no Sul do Garbe, em Mértola (GÓMEZ MARTINEZ, 1993: 779-786, 1994: || 3-132; MACIAS, 199|: 4| 8-420; TORRES, 1986: $193-$ 228, 1987: 77-79, TORRES et al., 1991: 497-536), em Palmela (FERNANDES et al., 1993), na cidade de Évora (TEICHNER, 1994: 336-358), na Cidade das Rosas, Serpa (RETUERCE VELASCO, 1986: 85-92), no castelo de Juromenha (CORREIA et al., 1992: 82-83), no castelo de Noudar, Barrancos (REGO, 1994: fig. 6), no castelo de Moura (MACIAS, 1993: I30, fig. 5), no Castro de Nossa Senhora da Cola, Ourique (VIANA, 1959:3-48, 1960: 138-231), no sítio de Mesas do Castelinho, Almodôvar (GUERRA et al., 1993: 98), nas camadas 8 e 5 de Silves (GOMES, 1988: 181-202), no Cerro da Vila, Vilamoura, Loulé (MATOS, 1983: 375-390; 1986: 149-154), na Quinta do
Lago (Loulé), no Vale do Bôto (Castro Marim), e em alguns dos sítios que prospectei na Serra algarvia, por exemplo no Cerro da Horta do Brejo, nas Alcarias de Marim, no sítio do Gatacho e nos Alcariais de Monte Argil.

Os ataifores de superfícies meladas com decoração a óxido de manganés têm bordos muito variados: adelgaçantes, boleados direitos ou com inflexão externa, espessados externamente, de perfil semicircular e triangular, ou, ainda, com leve aba exvertida. $\bigcirc$ corpo apresenta paredes curvo-convexas, mais ou menos acentuadas, por vezes também com ressalto na ligação com a base. $\bigcirc$ fundo possui um pé anelar de secção rectangular ou quase trapezoidal. Os temas decorativos mais comuns são as flores de lótus, os círculos secantes, os simples traços geométricos e, num único exemplar, inscrição epigráfica (Est. II. 13). Os fabricos, de boa qualidade, caracterizam-se por pastas compactas, rosadas e alaranjadas.

Encontram-se em numerosos sítios, mesmo em recolhas de superfície, sendo, por isso, impossível indicar todos os locais onde se registaram. Apontam-se apenas alguns em território nacional: Mértola, integradas no século $\mathrm{XI}$ (TORRES, 1987: 39; TORRES et al., 1991: 506, nos 016 a 021); Alcaria Longa, Mértola (BOONE, 1992: 59, 5E, 5F, 5G); castelo de Juromenha (CORREIA et al,, 1992: 82-83); Cidade das Rosas, Serpa (RETUERCE VELASCO, 1986: 85-87, fig. 2e-f; 88, fig. 3.e-f); Cerro da Vila, Vilamoura, com típica decoração dos séculos $X / X I$, onde domina a flor e o bolbo de lótus (MATOS, 199 la: fig. 2, 5 e 7; 199 lb: 451, nº 00450078); castelo de Silves, sobretudo a partir da camada 4, datada dos reinos de taifas (GOMES, 1988: 206).

A série redoma está representada em escassos fragmentos, normalmente com superfícies vidradas. Alguns exemplares exumados nas camadas da $I^{a}$ fase podem, porém, incluir-se neste grupo, embora não sejam vidrados: um fragmento de bordo trilobado (Est. I. I6), de perfil boleado, acentuadamente esvasado, com arranque de asa sobrelevada; outro, a que falta o bordo (Est. I. 7), tem colo alto, cilíndrico e estreito, com ressalto em moldura a meio, corpo globular e fundo plano. Uma única asa, de 
secção romboidal, incompleta, provavelmente sobreelevada, parte a meio do colo e termina no bojo.

Aproximam-se da variante T1 6.3 de Gutierrez Lloret (1996: I09, fig. 38) e têm paralelos em peças com moldura no colo, normalmente vidradas, de Elvira, Granada (CANO PIEDRA, 1990, fig. 3), de Pechina, Almeria (ACIÉN ALMANSA et al,, 1989: fig. 5.5 e 6; FLORES ESCOBOSA et al., 1993: 19), ocorrendo também no nível I do forno de Bayyana, não vidradas, consideradas como precedentes das califais (CASTILLO GALDEANO et al., 1993: 92, lám. IX. 2, 93). Mas registaram-se também no nível II do forno de Bayyana, com menor variedade de formas (ibid.: I |0-। I I, lám. XIX.4).

As de superfície vidrada (Est. II. 22) ocorrem nas camadas da $2^{a}$ fase e possuem colo cilíndrico muito alto, estreito e com saliência em moldura a meio. $O$ corpo pode ser esférico ou globular. A asa é sobreelevada, parte do colo e termina no bojo. As pastas são homogéneas de cor alaranjada, e as superfícies, meladas claras e amareladas, têm decoração com traços a óxido de manganés.

Têm paralelos em peças dos séculos X/XI. São análogas à forma VI6.I de Gutierrez Lloret (1996: 128, fig. 53), ao tipo I de Azuar Ruiz (1986: 186), às redomas de Pechina (FLORES ESCOBOSA et al., 1993: 19), de Elvira (CANO PIEDRA, 1990: fig. 4, 1181 e 1182) e de Dénia (AZUAR RUíZ, 1989: 247-248, fig. 139). Registam-se também em Mértola (TORRES, 1987: 59-61) e em Moura (MACIAS, 1993: I32, fig. 8).

A série jarrito integra pequenas peças com única asa e que podem ter, em alguns casos, um bico no bordo. Um grupo apresenta caneluras no colo (Est. I. 8; Est. II. 4), em fabricos grosseiros, com pastas granulosas de cor ocre acastanhado ou alaranjado. Recolheram-se sobretudo nas camadas mais antigas e são idênticos à forma M20.I de Gutierrez Lloret, proveniente de El Zambo (GUTIERREZ LLORET, 1988: 88, Z9; 1996: 91). Têm também paralelos em Conimbriga (ALARCÃO, 1975: pl. XLIII, n 830) e em Mesas do Castelinho, Almodôvar (FABIÃO et al, 1991: 317 , fig. 6. ( e 2).
Outros, de colo alto cilíndrico, têm corpo troncocónico invertido, com caneluras (Est. Il. 3). Possuem pastas e superfícies homogéneas, mas friáveis, de cor creme esbranquiçada ou amarelada. Têm paralelos nos jarritos do sudeste espanhol, datados a partir do século IX, iguais aos de El Zambo (GUTIERREZ LLORET, 1988: 89, ZI2, ZI3, ZI5), integrados na forma T20.2 (ibid., 1996: II4, fig. 42). Encontram-se também em Niebla, datados dos séculos XIXI (OLMO ENCISO, 1986: 137, fig. I. e-f, fig. 2. b-c), em Vascos (IZQUIERDO BENITO, 1996: 160, fig. 2. I), no forno de San Nicolas (NAVARRO PALAZÓN, 1990: fig. 7. 22) e na área urbana de Múrcia (ibid., 1986: 155, n 333), um dos exemplares decorado com pintura de tom avermelhado (ibid.: n 332).

Dois fragmentos de bojo, exumados nas camadas da I a fase, têm superfícies vidradas: um, do Castelo Velho de Alcoutim (Est. I. I I), apresenta vidrado transparente na superfície externa, sobre engobe amarelado, e esverdeado no interior; o segundo, do Castelo das Relíquias, tem as duas superfícies vidradas a verde (Est. I. 10). Correspondem a fabricos de boa qualidade, de pasta esbranquiçada ou creme acinzentada, e têm decoração, com incisões sobre caneluras salientes ou sobre finas aplicações plásticas.

Devem ter pertencido a formas da série 23 definida por Gutierrez Lloret, nas variantes V23. I.I e V23.I.2, da segunda metade do sécuIo IX (GUTIERREZ LLORET, 1996: I23-I24, fig. 56). Registaram-se no Mosteiro de Melque (CABALLERO ZOREDA et al., 1980: 118 e 120, fig. $27 \mathrm{n}^{\circ}$ (81), em Vascos (IZQUIERDO BENITO, 1979: 344, 1983: 368), em Calatalifa (RETUERCE VELASCO, 1984: I22, fig. 4. c e fig. 10), em El Castillon (MOTOS GUIRAO, 1986: 397 e 404, fig. 6. 3), em Pechina (FLORES ESCOBOSA et al., 1993: 87), nas produções de Bayyana, nos níveis inferiores ao período califal (ACIÉN ALMANSA et al., 1989: 129, fig. 3, 2 e 14; CASTILLO GALDEANO et al., 1987: 546, lám. I.4), em Bezmiliana e na Plaza de la Marina (ACIÉN ALMANSA et al., 1989: 128, 131,129 - fig. 3. 2 e 14, î̃NIGUEZ et al., 1993, 3, lám. 6), no cemitério de San Nicolas (Múrcia), datados dos séculos $X / X I$, com decoração incisa sobre caneluras horizontais e superfícies vidradas e não vidradas (NAVARRO PALAZÓN, 
1986: 157, n³39; I58, n 340 e 34I), assim como em Ceuta (FERNÁNDEZ SOTELO, 1988, I26, fig. 26.c).

Na série jarrita incluem-se dois grupos. $\mathrm{O}$ primeiro caracteriza-se por ter corpo globular baixo (Est. I. 9) e estrangulamento junto do fundo plano ou por ter corpo quase bitroncocónico (Est. II. 7), também com fundo plano. As duas asas partem do colo, logo abaixo do bordo, e terminam quase na base da peça. Têm pastas homogéneas, de cor alaranjada ou castanha avermelhada, e superfícies alisadas, de cor alaranjada. Podem apresentar restos de decoração pintada a branco.

As peças com carena baixa têm paralelos em alguns exemplares de Silves, recolhidos na camada 8 (GOMES, 1988: 195, n Q3/C8-33, Q3/C834), de Mesas do Castelinho (FABIÃO et al., 1991: 319 , fig. 8. 3) e do Castelo de Palmela (FERNANDES et al., 1993: 49, n I I0). Em Mértola, associam-se a contextos califais (TORRES, 1987: 15, TORRES et al., 1996: fig. 10). São também idênticas a peças de Niebla, com pintura negra sobre pasta clara, datadas dos séculos XIXI (PÉREZ MACIAS et al., 1993: 59, fig. 10).

O segundo grupo integra as decoradas a corda seca parcial (Est. II. 8). O corpo pode ser globular ou globular achatado, e o fundo plano ou com pé anelar pouco diferenciado. As pastas são muito homogéneas, de tonalidades creme amareladas ou esbranquiçadas. As superfícies, alisadas e com engobe da cor da pasta, caracterizam-se pela decoração a corda seca parcial que se desenvolve no colo e/ou a meio do bojo.

Têm paralelos em jarritas da Marca Superior, datadas de finais do século $X$ e da primeira metade do século XI (ESCO et al, 1988: 89, n 5 I; 90, n⿳ 52; 97, n 59), em exemplares recolhidos na área urbana de Múrcia, datados dos séculos XI/XII (NAVARRO PALAZÓN, 1986: I54, nº 330, 24024I) e abundam entre as cerâmicas de Málaga (PUERTAS TRICAS, 1989) e de Almeria, onde o exemplar M é precisamente igual ao recolhido no Castelo das Relíquias (DOMÍNGEZ BEDMAR et al., 1987: 570-57I). Encontram-se entre as produções de Bayyana (Pechina), no nível II do forno (CASTILLO GALDEANO et al., 1993: 109, lám. $X V I I I .7)$.

\subsection{Recipientes de armazenamento e consumo}

Indicam-se, entre os recipientes de armazenamento e consumo, os grandes cântaros (jarras) e formas idênticas, de menores dimensões -bilhas, cantarinhas ou infusas- que serviam para guardar água e a levar à mesa. Seguem-se as grandes talhas (tinajas) e os pequenos potes (orzas).

A série jarra (cântaro) caracteriza-se por bordos com inflexão externa e lábios arredondados. Os colos são altos, o corpo ovóide e o fundo plano. As duas asas, verticais, partem do colo e terminam na parte alta do bojo (Est. II. 20). As pastas são porosas, de tonalidade ocre alaranjada. Podem apresentar decoração incisa no ombro, com linhas onduladas ou, ainda, traços de pintura, normalmente a branco, que se encontra sobretudo nas asas e/ou no ombro.

Este tipo de recipientes é muito comum, com variantes próprias a cada região, como pode observar-se no mapa de distribuição apresentado por Bazzana (1979: 152). Os exemplares até agora identificados podem atribuir-se ao período califal e dos reinos de taifa, umas vezes com decoração incisa no ombro, outras com traços de pintura a branco. Contudo, peças com perfil idêntico exumaram-se em Fresnada de Cuellar (Segóvia), entre as cerâmicas pós-7II (CABALLERO ZOREDA, 1989: 85, fig. 7), na camada 8 de Silves, atribuída ao século VIII (GOMES, 1988: 193) e no Cerro da Vila, Vilamoura (MATOS, I99।: 448, nº 0055). Têm perfil igual a produções do forno de San Nicolas, Múrcia (NAVARRO PALAZÓN, 1990: fig. 8. 24) e a peças vidradas e decoradas a verde e manganés, incluídas na série VII.I de Gutierrez Lloret (1996: I26, fig. 5 I), como acontece em cântaros de Medina Azahara.

Entre as de menores dimensões (bilhas ou cantarinhas) destaca-se um grupo, de pastas homogéneas, mas bastante friáveis, de cor branca ou creme rosada, e superfícies alisadas de cor esbranquiçada (Est. II. 15), que podem apresentar decoração a óxido de ferro (Est. I. 15). Possuem duas asas de secção oval; os bordos têm inflexão externa, de lábio oblíquo; os colos 
são alongados, em ligação directa com o corpo, de perfil ovóide, que pode apresentar caneluras irregulares na parte inferior (Est. II. 15). Peças semelhantes recolheram-se na alcáçova de Mértola, em contextos dos séculos XIXI (KHAWLI, 1993: 72,9 e 10).

Um segundo grupo caracteriza-se por fabricos de boa qualidade, com pastas bem depuradas, de cor creme amarelada ou esbranquiçada. Uma, incompleta, foi recolhida na latrina do Castelo das Relíquias (Est. II. 2I) e apresenta decoração a verde e manganés, com restos de vidrado transparente, sobre engobe, na superfície externa; outra, também incompleta, do Castelo Velho de Alcoutim (Est. II. 16), tem corpo globular com caneluras e decoração em corda seca parcial. Possui uma asa sobrelevada, que parte do colo e termina a meio do bojo. Ocorrem em contextos dos séculos $X / X I$ e a segunda tem paralelos entre as cerâmicas califais de Elvira, Granada (LLUBIÁ, 1973: 39, n 18) e de Almeria (FLORES ESCOBOSA et al., 1993: 20)

Os fragmentos das séries tinaja (Est. I. 17) e orza (Est. I. 12, 13 e 14) pertencem a fabricos grosseiros, locais ou regionais, com pastas pouco compactas, granulosas e de tonalidades pardas ou ocre acastanhadas, raramente alaranjadas. Exumaram-se principalmente nas camadas da $\mathrm{I}^{\mathrm{a}}$ fase e, na maior parte dos casos, o bordo tem um sulco interno (Est. I. I2). A maior parte dos fragmentos apresenta decoração, com aplicação de cordão plástico digitado ou ungulado, no bordo (Est. I. 13), no colo (Est. I. I4) ou no ombro (Est. I. 17).

As grandes tinajas (talhas) aproximam-se da série MI0.2 de Gutierrez Lloret, com cronologias de finais do século IX e da primeira metade do século X (GUTIERREZ LLORET, 1996: 8889, FIG. 23), das de Pechina (ACIÉN ALMANSA et al,, 1989: 133, fig. 6.7, ibid., 1990: 163, fig. 7) e das produções de Bayyana (CASTILLO GALDEANO et al., 1993: I I4, lám. XXI). Estão também presentes em Jaén (SALVATIERRA CUENCA et al., 1993: 255, fig. 7), em El Castillón (MOTOS GUIRAO, 1991: 55-59, 62, fig. 13; 1993: 223), em El Maraute (GÓMEZ BECERA, 1993: 187, fig. 3) e em Aroche (FERNÁNDEZ GABALDÓN, 1990: 364-365, 368-369). Os paralelos para a série orza (pote) podem encontrar-se, entre outros sítios, no mosteiro de Melque (CABALLERO ZOREDA, 1980: 99, fig. 17. 66). Ocorrem com frequência entre os achados de superfície, nos povoados de altura da Serra algarvia, e são do mesmo tipo de exemplares da Cidade das Rosas, Serpa (RETUERCE VELASCO, 1986: 89, fig. 4.E), do Montinho das Laranjeiras, Alcoutim (COUTINHO, 1993: EI5-03) e do Castelo dos Mouros, Sintra (COELHO, 1996: Est. IV I-2).

\subsection{Outros recipientes}

Distinguem-se, ainda, as séries alcadafe (alguidar), tapadera (tampa), candil (candeia) e arcaduz (alcatruz).

Em escassos fragmentos, registaram-se, nas camadas mais antigas, pequenos alguidares ou bacias, que se caracterizam por apresentar um bordo em aba plana ou oblíqua, com leve espessamento interno e perfil externo rectangular, com lábio desenvolvido (Est. I. 18). Este é levemente convexo e tem, normalmente, uma decoração incisa, com traços em ondulado ou em ziguezague. $\bigcirc$ fabrico é manual/torno baixo, as pastas grosseiras e bastas, ocre acastanhadas ou acinzentadas.

Têm paralelos em Conimbriga, nos níveis de destruição (ALARCÃO, pl. XXXI, 649A, pl. XXXII, 658); em Cancho del Confessionario, Madrid, em contextos dos séculos V/VII (CABALLERO ZOREDA, 1989: fig. 1.13); no povoado de altura de Cabeza de Navasangil (Ávila), também com decoração incisa ondulada no bordo (LARRÉN IZQUIERDO. 1989: 64, fig. 6.124). Mas surgem também entre as cerâmicas dos séculos VII a $X$ de Villajimena, Palencia (BOHIGAS ROLDÁN et al., 1989: 38, fig. 2. II).

O conjunto mais representativo pertence a alguidares com bordos desenvolvidos e espessados externamente (Est. II. I4), com perfil oblíquo semicircular ou com tendência triangular. As pastas são pouco homogéneas, de cor castanha, avermelhada ou alaranjada, em certos casos com núcleo cinzento. As superfícies são alisadas ou engobadas e brunidas.

Pertencem ao tipo clássico, com bordo em aba boleada ou triangular, como a variante $A$ da 
série 9 de Rosselló-Bordoy (1987: 60-61, fig. 13). Têm abundantes paralelos, desde o período tardo-romano, como em Conimbriga (ALARCÃO, 1975: pl. XXXI, 656, 656A). Manteve-se, com poucas alterações formais, durante todo o período islâmico. Alguns, com engobe de cor castanho avermelhado de almagre e espatulado interno, têm paralelos em ambientes geográficos e cronológicos muito próximos de Alcoutim, na província de Huelva, no Castelo da Cerca Alta, Cerro do Andévalo, e no Cerro del Castillejito, Monaster la Real (PÉREZ MACÍAS et al., 1988: 334).

A maioria das tampas (Est. II. 19) aproximase da variante 8A definida por Rosselló. Nos níveis da I a fase de ocupação encontraram-se, porém, exemplares de fabrico manual, com disco plano e asa grosseira, de secção circular (Est. I. 19). Outras, quer nos níveis da I a fase, quer nos da $2^{a}$, podem possuir ressaltos na parte superior do disco (Est. I. 20) ou ter bordo elevado, com aplicação plástica digitada (Est. II. 18). As planas, em disco, integram-se nas séries M30.I I. M30. I.2 e M30.2 de Gutierrez Lloret, nomeadamente em Begastri, também com decorações impressas e incisas (GUTIERREZ LLORET, 1994: 148 e 149, fig. 3), na Alcudia de Elche (ibid., 1988:59-60), em El Zambo (ibid., 1988: 88) e na Rábita de Dunas de Guardamar (AZUAR RUÍZ et al., 1989: 114). Registam-se também em Vascos, (IZQUIERDO BENITO, 1986: I20, fig. 7. 4), em Alcalá la Vieja (ZOZAYA, 1985: 448 e 452, fig. 26.a), em Pechina (ACIÉN ALMANSA et al., 1989: 126, fig. 1.3, 128), em Almeria (DOMÍNGUEZ BEDMAR et al., 1987, lám. I e II) e em El Castillon (MOTOS GUIRAO, 1991, fig. 14. 1-14). Aproximam-se de exemplares de Conimbriga, com decoração incisa na parte superior do disco (ALARCÃO, 1975: pl. XIX. 38I, pl. LII. 925), aplicações plásticas (ibid.: pl. LII. 922A), caneluras ou molduras salientes (ibid.: pl. LII. 923) e bordos sobrelevados (ibid.: pl. LI. 987).

As candeias (série candil) apresentam pouca diversidade morfológica distinguindo-se, porém, um fragmento de bico curto, em superfícies não vidradas, recolhido no nível 5 do Castelo Velho de Alcoutim (Est. I. 2I). Os outros exemplares (Est. II. 17), da $2^{\text {a }}$ fase de ocupação, podem apresentar superfícies vidradas de cor melada, com decoração a óxido de manganés, ou, com mais frequência, superfícies engobadas e decoração a corda seca parcial. $\bigcirc$ fragmento de bico aproxima-se da série T33.3.2 de Gutierrez Lloret, fabricada a partir dos séculos VIII/IX até ao século X (GUTIERREZ LLORET, 1996: I24, FIG. 50), semelhante a exemplares de El Castillon (MOROS GUIRAO, 1991: 49, fig. 16) e a um exumado na camada 8 de Silves, (GOMES, 1988: 186, Q3/C8-II). Os outros são abundantes em contextos califais e dos reinos de taifa.

Até ao momento, apenas se recolheu parte de um alcatruz, recolhido no nível 3 do Castelo Velho de Alcoutim (Est. II. 23). Possui fundo plano, estreito e irregular; corpo levemente troncocónico, quase tubular, com um sulco a meio para a ligação ao engenho hidráulico; pasta de boa qualidade e superfícies alisadas, de cor alaranjada. Encontra paralelos, por exemplo, nas produções de Bayyana, de finais do período emiral e inícios do califado (CASTILLO GALDEANO, 1993: I | 3, lam. XXII, I a 5).

\section{CONCLUSÕES}

As cerâmicas que se apresentaram podem dividir-se, quanto aos tipos de fabrico, em peças produzidas a torno baixo de rotação descontínua (torneta) e fabricadas a torno alto de rotação regular. As primeiras ocorrem sobretudo nas camadas mais antigas, em 29\% no Castelo Velho de Alcoutim e 24\% no Castelo das Relíquias. Caracterizam-se por frabricos locais e regionais, de pastas grosseiras, de tons ocre acastanhado e alaranjado, em argilas pouco depuradas, com abundantes desengordurantes vegetais e minerais, de grãos médios e grossos, com areias de ribeira, xisto e quartzo triturados. As superfícies são alisadas, podem possuir engobe da cor da pasta ou em almagre, no interior de formas abertas; decorações incisas ou, ainda, aplicação de cordões plásticos digitados, nas partes mais débeis das formas fechadas, nomeadamente junto do bordo, no colo ou nas paredes do corpo das talhas e potes.

Os recipientes produzidos a torno alto, de rotação regular, dominam nos níveis da $2^{a}$ fase de ocupação, em 76\% no Castelo das Relíquias e 7I\% no Castelo Velho de Alcoutim. Corres- 
pondem a fabricos com argilas depuradas, de textura habitualmente compacta ou ligeiramente granulosa, com abundantes e variados desengordurantes, predominando os de grãos finos e médios, com pastas e superfícies cinzentas, castanhas, alaranjadas ou avermelhadas. Para além do simples alisamento, algumas formas abertas levaram engobe, da cor da pasta ou em almagre, e brunido na superfície interna; outras, como os cântaros e os pucarinhos/pucarinhas, levaram simples aguada da cor da pasta, sobre a qual se aplicava decoração, com traços e meandros de pintura.

Um conjunto, recolhido nos níveis da $I^{a}$ fase, pertence seguramente a importações, possivelmente do Sul da actual Andaluzia, com pastas depuradas, mas de textura porosa ou friável, que se desagrega facilmente em contacto com as mãos, e têm abundantes desengordurantes minerais, de grãos muito finos, pouco visíveis a olho nu. A cor da pasta varia entre o branco acinzentado, creme amarelado, verdoso e rosado. Associam-se a produções com superfícies caneladas ou pintadas, normalmente com óxido de ferro, assim como a fragmentos com superfícies vidradas monocromas de cor verde ou castanho chocolate, sobre decoração incisa, possíveis produções de Pechina.

Exclusivas dos níveis da $2^{\mathrm{a}}$ fase são as peças decoradas a verde e manganés e a corda seca parcial. Pertencem a fabricos de boa qualidade, com pastas cremes, esbranquiçadas, rosadas e acinzentadas claras. Os vidrados podem ser transparentes, sobre engobe branco ou amarelado; translúcidos, de tons amarelo limão ou esverdeado, também sobre engobe; opacos e brilhantes, sobretudo melados, com diversas tonalidades, desde melado claro, quase amarelo e melado vivo, sobretudo nas que apresentam simples decoração com traços de manganés. Aparentemente, as peças mais tardias, já plenamente dos reinos de taifa ou de finais deste período, na transição para época almorávida, serão o fragmento de jarra de filtro com decoração a corda seca parcial e o ataifor de vidrado melado e decoração epigráfica.

Pelas evidências arqueológicas, torna-se seguro afirmar que estes castelos foram edificados no período emiral, possivelmente no reinado de Abd al-Rahmam II (822-852) ou, mais provavelmente, no de Muhammad I (852-886), hipótese já formulada por Soler e Zozaya (1989: 267-268) em relação ao Castelo das Relíquias. De facto, se pensarmos que, no século IX, 'Abd al-Rahman II manda que se fortifiquem as costas, se constrói o ribat de Almeria e, no emirato de Muhammad I, se verificou uma intensa actividade de construção defensiva -os rubut, já indicados, por exemplo, por Juan Souto (1994: 351-360) e por Carmen Martínez Salvador (1994: 36I-370)- devemos compreender que a ampla costa do Garbe devia ter possuído várias fortificações costeiras, algumas com finalidade de ribat.

Concretamente no Algarve, é possível que a partir de meados e finais do século IX, para além de reconstruções nos amuralhados urbanos se fundassem novas povoações, na defesa do litoral, como será o caso, por exemplo, de Cacela (Qastalla) e da alcaria de Tavira (Talabira), citada, mais tarde, por Edrici. É a partir da segunda metade do século que começam a construir-se outros pequenos castelos, designados genericamente por hisn (pl. husum), nos quais se inclui, na defesa do Guadiana, o Castelo Velho de Alcoutim. Esta fortaleza omíada, centro de um território rural e mineiro do iqlim de Cacela, deve ter sido, de início, um simples fortim ou possível ribat ${ }^{2}$ que controlava a via fluvial do Guadiana, precisamente a meio do percurso entre a cidade de Mértola e o litoral.

No primeiro período de ocupação dos dois husum do Alto Algarve Oriental devem ter-se construido as muralhas, cisterna e edifícios identificados com os estratos arqueológicos da $I^{a}$ fase, que se encontram afastados das muralhas deixando um estreito adarve, bem visível

2 Podemos pensar, ainda que com reservas, que primeira função do Castelo Velho de Alcoutim seria a de ribate, se tivermos em atenção que, embora afastado do litoral, tem localização estratégica sobre o rio. Acrescente-se o facto de, em 859, os Normandos, depois de atacarem as costas de Ossónoba, terem subido o Guadiana para provocar razias na kura de Beja. 
principalmente no Castelo Velho de Alcoutim (Est. IV. I), fortificação com planta semelhante a Almizerát, embora não apresente torres semicirculares como no fortim valenciano (BAZZANA, 1990: 87-108).

Numa segunda fase, possivelmente a partir de meados do século $X$, verificam-se reestruturações, com edifícios adossados ao interior das muralhas (Est. IV. I) e, no Castelo Velho de Alcoutim, remodelou-se, possivelmente já no século $\mathrm{Xl}$, a porta principal (com pequeno átrio interno, onde se recolheram várias dezenas de pontas de lança e de besta), que passa a estar protegida por um torreão em L, adossado à muralha voltada para o Guadiana. Ainda durante os finais do período califal ou, mais seguramente, no período dos reinos de taifas, acaba por se construir um grande edifício central, onde anteriormente teria existido um pátio. Esta reestruturação do espaço ter-se-á mantido durante os reinos de taifas para, depois, ser novamente objecto de destruições e consequente abandono, em momento ainda impreciso, o mais tardar durante os finais deste período ou nos inícios da ocupação almorávida, visto estarem completamente ausentes as cerâmicas características dos séculos XII/XIII.

Do ponto de vista do território, podemos concluir que, para além do núcleo urbano de Cacela (hisn Qastalla), implantado no litoral e referido nas fontes árabes, existiam outros husun omíadas no Algarve Oriental, situados nas proximidades de áreas mineiras, na Serra: o Castelo Velho de Alcoutim (Est. III. I), sobranceiro à principal via fluvial que foi o Guadiana; e - Castelo das Relíquias (Est. III. 2), junto a um caminho que atravessava a ribeira do Vascão em direcção a Via Glória e Mértola. Foram construídos em pedra seca argamassada com terra, no cimo de serros bem diferenciados na paisagem, e apresentam planta poligonal regular, com torres quadrangulares adossadas às muralhas. O Castelo Velho de Alcoutim (Fig. I, Est. III. I) tem um reduto superior com $32 \mathrm{~m}$ por 22 $\mathrm{m}$ de lado e o Castelo das Relíquias (Fig. 2, Est. III.2) apresenta $40 \mathrm{~m}$ por 34/35 m de lado. Uma segunda cintura de muralhas, com traçado igualmente rectilíneo, envolve as fortificações superiores e protege um pequeno núcleo urba- no, descendo para as encostas voltadas, respectivamente, para o Guadiana e para a ribeira do Vascão.

Estão aproximadamente a 22 km de distância e dominavam espaços regionais com um território que abarcaria, teoricamente, um raio circundante máximo de cerca de 10 a $11 \mathrm{~km}$. Em torno destes castelos se foi organizando o povoamento rural, aproveitando os recursos de que dispunham: áreas de terrenos agrícolas, propícias fundamentalmente para pequenas hortas situadas, no caso do Castelo Velho de Alcoutim, junto do rio Guadiana e da ribeira de Cadavais, e no Castelo das Relíquias em boas rechãs da ribeira do Vascão; áreas de matos propícios à criação de gado e exploração de madeira; zonas de mineração, sobretudo na área envolvente ao Castelo Velho de Alcoutim e na zona de Lotão e Laborato, próximo do Castelo das Relíquias.

\section{BIBLIOGRAFÍA}

ACIÉN ALMANSA, Manuel (1986): "Cerámica a torno lento en Bezmiliana. Cronología, tipos y difusion", I C.A.M.E., vol. IV (Huesca, 1985), Diputación General de Aragón, Departamento de Cultura y Educación, Zaragoza, pp. 243-267.

(1993): "La cultura material de época emiral en el Sur de Al-Andalus. Nuevas perspectivas", La cerámica altomedieval en el Sur de al-Andalus, Primer Encuentro de Arqueología y Patrimonio, Granada, pp. I53-I72.

ACIÉN ALMANSA, Manuel e MARTÍNEZ MADRID, Rafael (1989): "Cerámica islámica arcaica del Sureste de AlAndalus", B.A.M., n 3, Asociación Española de Arqueología Medieval, Madrid, pp. I23-135.

ACIÉN ALMANSA, Manuel, CASTILLO GALDEANO, Francisco e MARTÍNEZ MADRID, Rafael (1990): "Excavación de un barrio artesanal de Bayyana (Pechina, Almería)", Archéologie Islamique, vol. I, Maisonneuve \& Larose, Paris, pp. 147- 168.

ACIÉN ALMANSA, Manuel, CASTILLO GALDEANO, Francisco et al. (1995): Evolución de los tipos cerámicos en el S.E. de Al-Andalus. "V C.C.M.M.O.", (Rabat, 199I), I.N.S.A.P., Rabat, pp. 125-139.

ALARCÃO, J. de (1975): "La céramique commune locale et régionale", Fouilles de Conimbriga, V, Diffusion E. de Boccard, Paris. 
ALVARÉZ DELGADO, Yasmina (1987): "Cerámicas comunes con y sin decoración, siglo IX. Ercávica (Cuenca)", II C.A.M.E., vol. II, Madrid, pp. 403-4I 2.

(1989): "Cerámicas del siglo IX de Arcávica (Cuenca)". B.A.M., $n^{\circ}$ 3; Asociación Española de Arqueología Medieval, Madrid, pp. 109-121.

AZUAR RUIZ, Rafael (1986): "Apunte para un ensayo de evolución crono-tipológica de la redoma hispanomusulmana", II C.C.M.M.O, Ministerio de Cultura, Madrid, pp. I85- 87.

(1989): Denia islamica. Arqueología y poblamiento. Instituto de Cultura Juan Gil - Albert, Alicante.

AZUAR RUIZ, Rafael et al. (1989): La rábita de las Dunas de Guardamar (Alicante). Diputación Provincial de Alicante, Museo Arqueológico, Alicante.

BAZZANA, André (1979): "Céramiques médiévales: les méthodes de la description analytique appliquees aux productions de l'Espagne orientale", M.C.V., vol. XV, Paris, pp. |35- 185.

(1980): "Céramiques médiévales: les méthodes de la description analytique appliquées aux production de l'Espagne orientale: II. Les poteries décorées. Cronologie des productions médiévales", M.C.V., vol. XVI, Paris, pp. 57-95.

(1990): "Un fortin omeyyade dans le Shark Al-Andalus", Archéologie Islamique, vol I; Maisonneuve \& Larose, Paris, pp. 87- 108.

BOHIGAS ROLDÁN, Ramón e RUÍZ GUTIÉRREZ, Alicia (1989): "Cerámicas visigodas de poblado en Cantabria y Palencia", B.A.M., nº 3; Asociación Española de Arqueología Medieval, Madrid, pp. 3।-5।.

BOONE, James (1992): "The first two seasons of excavations at Alcaria Longa: a caliphal - taifal period rural settlement in the Lower Alentejo of Portugal", Arqueologia Medieval, I, Campo Arqueológico de Mértola, ed. Afrontamento, Porto, pp. 51-64.

CABALLERO ZOREDA, Luis (1980): La iglesia y el monasterio visigodo de Santa Maria de Melque (Toledo). Arqueología y arquitectura. San Pedro de la Mata (Toledo) y Santa Comba de Bande (Orense). E.A.E., n 109, Ministerio de Cultura, Madrid.

(1989) "Cerámicas de "época visigoda y postvisigoda" de las provincias de Cáceres, Madrid y Segovia", B.A.M., $n^{\circ}$ 3, Asociación Española de Arqueología Medieval, Madrid, pp. 75- 107.

CANO PIEDRA, Carlos (1990): "Estudio sistemático de la cerámica de Madinat Ilbira", Cuadernos de la Alhambra, n 26, Granada, pp. 25-68.

(1993): "La cerámica de Madinat Ilbira", La cerámica altomedieval en el Sur de Al-Andalus, Primer Encuentro de Arqueología y Patrimonio, Granada, pp. 273-283.
CASTILLO ARMENTEROS, J. C. (1996): "La cerámica emiral de la campiña de Jaen", Arqueología y Território Medieval, 3, Universidad de Jaen, pp. 191-220.

CASTILLO GALDEANO, F., MARTÍNEZ MADRID, R. e ACIÉN ALMANSA, M. (1987): "Urbanismo y industria en Bayyana (Pechina, Almería)", II C.A.M.E., vol. II, Madrid, pp. 538-548.

CASTILLO GALDEANO, F. e MARTÍNEZ MADRID, R. (1993): "Producciones cerámicas en Bayyana", La cerámica altomedieval en el Sur de Al-Andalus, Primer Encuentro de Arqueología y Patrimonio, Granada, pp. 67-116.

CATARINO, Helena (1988): Para o estudo da ocupação muçulmana no Algarve Oriental. Provas de Capacidade Científica, Coimbra (policopiada).

(1989): "Os sistemas defensivos muçulmanos do Algarve Oriental e o Castelo Velho de Alcoutim", III C.A.M.E., vol. II, Universidad de Oviedo, Oviedo, pp. 296-305.

(1994): "Arqueologia Medieval no Algarve Oriental. Os castelos de Alcoutim", Arqueología en el Entorno del Bajo Guadiana, Universidade de Huelva, Huelva, pp. 657-67I.

C.E.V.P.P. (|99|): "Ceramicas de epoca visigoda en la Peninsula Iberica. Precedentes y perduraciones", IV C.C.M.M.O., (Lisboa, 1987), ed. Campo Arqueológico de Mértola, pp. 49-67.

COELHO, Catarina (no prelo): "A ocupação islâmica do Castelo dos Mouros (Sintra)- interpretação comparada", $2^{\circ}$ Congresso de Arqueología Peninsular, (Zamora, Setembro de 1996).

CORREIA, Fernando Branco PICARD, Christophe (1992): "Intervenção arqueológica no Castelo de Jurumenha - primeiros resultados", Arqueologia Medieval, I, Campo Arqueológico de Mértola, ed. Afrontamento, Porto, pp. 71-89.

COUTINHO, Helder M. R. ( 1993): "Cerâmica muçulmana do Montinho das Laranjeiras", Arqueologia Medieval, 2, Campo Arqueológico de Mértola, ed. Afrontamento, Porto, pp. 39-54.

DOMINGUEZ BEDMAR, Manuel (1987): "Madinat AlMaryya. El estudio preliminar de las cerámicas aparecidas en sus atarazanas", II C.A.M.E., vol. II, Madrid, pp. 567-577.

ESCO, Carlos et al. (1988): Arqueología islámica en la Marca Superior de Al-Andalus. Diputación Provincial de Huesca, Zaragoza.

FABIÃO, Carlos GUERRA, Amilcar (|99|): O povoado fortificado de "Mesas do Castelinho", Almodôvar", Actas das IV Jornadas Arqueológicas, (Lisboa 1990), A.A.P., Lisboa, pp. 305-319.

FERNANDES, C. CARVALHO, R. (1993): Arqueologia em Palmela. 1988/92. Catálogo da Exposição, Câmara Municipal de Palmela. 
FERNÁNDEZ GABALDÓN, Susana (1990): "Primeros datos arqueologicos acerca del Aroche hispanomusulman (Aroche, Huelva). Estudio de los materiales ceramicos recogidos en superficie", Huelva Arqueológica, XII; Diputación Provincial de Huelva, Huelva, pp. 309-377.

FERNÁNDEZ SOTELO, Emilio (1988): Ceuta medieval. Aportación al estudio de las cerámicas (S. X-XV). 3 vols, Trabajos del Museo Municipal, Ceuta.

FLORES ESCOBOSA, Isabel et al. (Coord de), (1993): Vivir en Al-Andalus. Exposición de cerámica (S. IX-XV). Instituto de Estudios Almerienses, Diputación Provincial de Almeria/Almediterránea, Granada.

FUERTES SANTOS, Ma del Camino e GONZALEZ VIRSEDA, M. (1993): "Avance al estudio tipológico de la cerámica medieval del yacimiento de Cercadilla, Córdoba. Materiales emirales", IV C.A.M.E., Sociedades en Transición, vol. III, Alicante, pp. 77I-778.

(1994): "Nuevos materiales cerámicos emirales de Cercadilla (Córdoba): ensayo tipologico", A.A.C., vol. 5 , Universidad de Córdoba, Córdoba, pp. 277-30I.

GALVE IZQUIERDO, Pilar (1988): "Aproximación al estudio de la cerámica de epoca emiral en la ciudad de Zaragoza", Caesaraugusta, vol. 65, Zaragoza, pp. 235-26I.

GOMES, Rosa Varela (1988): Cerâmicas muçulmanas do Castelo de Silves. "Xelb", I, Silves.

GOMES, Rosa Varela e GOMES, Mário Varela (1989): "Dispositivos defensivos de Silves (Algarve, Portugal)", III C.A.M.E., vol. II, Universidad de Oviedo, Oviedo, pp. 287 295.

GÓMEZ BECERRA, Antonio (1993): "Cerámica a torneta procedente de "El Maraute" (Motril). Una primera aproximación a la cerámica altomedieval de la costa granadina", La cerámica altomedieval en el Sur de Al-Andalus, Primer Encuentro de Arqueología y Patrimonio, Granada, pp. |73-19|.

GÓMEZ MARTíNEZ, Susana (1993): "Variantes técnicas y formales de la cerámica "verde y morado" de Mértola (Portugal)", IV C.A.M.E., Sociedades en transición, vol. III, Alicante, pp. 779-786.

(1994) "La cerámica "verde y morado" de Mértola (Portugal)", Arqueologia Medieval, 3, Campo Arqueológico de Mértola, ed. Afrontamento, Porto, pp. II3-132.

GUERRA, Amílcar e FABIÃO, Carlos (1993): Uma fortificação omíada em Mesas do Castelinho (Almodôvar)", Arqueologia Medieval, 2, Campo Arqueológico de Mértola, ed. Afrontamento, Porto, pp. 85- 102.

GUTIÉRREZ LLORET, Sonia (1988): Cerámica común paleoandalusí del Sur de Alicante (siglos VII-X). Ed. de la Caja de Ahorros Provincial, Alicante.
(1994): "La cerámica tosca a mano de los niveles tardíos de Begastri (siglos VI-VIII): avance preliminar", Antigüedad y Cristianismo I. Begastri, Monografías Historicas sobre la Antigüedad Tardía, Universidad de Murcia ( $2^{a}$ ed.)

(1996): La Cora de Tudmir de la Antigüedad tardía al mundo islámico. Poblamiento y cultura material. "Collection de la Casa de Velázquez", 57, Madrid-Alicante.

ÍNIIGUEZ SÁNCHEZ, Ma Carmen e MAYORGA, J. (1993): "Un alfar emiral en Málaga", La cerámica altomedieval en el Sur de Al-Andalus, Primer Encuentro de Arqueología y Patrimonio, Granada, pp. 117-138.

IZQUIERDO BENITO, Ricardo (1979): "Excavaciones en la ciudad hispano-musulmana de Vascos (Navalmoralejo, Toledo). Campañas 1975-1978", N.A.H., 7, Madrid, pp. 248-392.

(1986): "Tipología de la cerámica de Vascos", II C.C.M.M.O., ed. Ministerio de Cultura, Madrid, pp. I| 3-।25.

(1996): "Unas tenerías excavadas en la ciudad hispanomusulmana de Vascos (Toledo)", Arqueología y Território Medieval, 3, Universidad de Jaen, pp. I49-165.

KHAWLI, Abdallah (1993): "Introdução ao estudo das vasilhas de armazenamento de Mértola islâmica", Arqueologia Medieval, 2, Campo Arqueológico de Mértola, ed. Afrontamento, Porto, pp. 63-78.

LARRÉN IZQUIERDO, Hortensia (1989): "Materiales cerámicos de la Cabeza: Navasangila (Ávila)", B.A.M., n 3; Asociación Española de Arqueología Medieval, Madrid, pp. 53-74.

LLUBIÁ, Luis M. (1973): Cerámica Medieval Española. Nueva Colección Labor, ed. Labor, Barcelona (2 $2^{\mathrm{a}}$ ed.).

MACIAS, Santiago (199|): "Um conjunto cerâmico de Mértola - Silos 4 e 5", IV C.C.M.M.O., (Lisboa, 1987), ed. Campo Arqueológico de Mértola, pp. 405-427.

(1993): "Moura na Baixa Idade Média: elementos para um estudo histórico e arqueológico", Arqueologia Medieval, 2, Campo Arqueológico de Mértola, ed. Afrontamento, Porto, pp. 127- 157.

MARTÍNEZ SALVADOR, Carmen (1994): "Los rubut de al-Andalus: un ensayo de localización", Trabalhos de Antropologia e Etnologia, vol. 34 (3-4), Porto, pp. 361-370.

MATOS, José Luís de (1983): "Malgas árabes do Cerro da Vila", Arq. Port., vol. I, série IV, Lisboa, pp. 375-389.

(199|a): "Influências orientais na cerâmica muçulmana do Sul de Portugal", Estudos Orientais II. O legado cultural de Judeus e Mouros, Instituto Oriental, Lisboa, pp. 75-83.

(199|b): "Cerâmica muçulmana do Cerro da Vila", IV C.C.M.M.O., (Lisboa, 1987), ed. Campo Arqueológico de Mértola, pp. 429-456. 
MOTOS GUIRAO, Encarnación (1986): "Cerámica procedente del poblado de "El Castillón" (Montefrío, Granada)", I C.A.M.E., vol. IV, (Huesca, 1985), Diputación General de Aragón, Departamento de Cultura y Educación, Zaragoza, pp. 383-405.

(|99|): El poblado medieval de "El Castillón" (Montefrío, Granada). Monografía Arte y Arqueología, Universidad de Granada, Granada.

NAVARRO PALAZÓN, Julio (1986): La cerámica islámica en Murcia. Vol. I: Catalogo; Ayuntamiento de Murcia, Murcia.

(1990): "Los materiales islámicos del alfar antiguo de San Nicolás de Murcia", Fours de potiers et 'testares' médiévaux en Méditerranée Occidentale, Casa de Velásquez, Série Archéo-logie XIII, Madrid, pp. 29-43.

OLMO ENCISO, Lauro (1986): "Cerámica común de época hispanomusulmana en Niebla", II C.C.M.M.O., ed. Ministerio de Cultura, Madrid, pp. I35-I39.

PÉREZ MACIAS, Juan Aurelio e BEDIA, Juana (1988): "Avance al estudio de los recintos fortificados islámicos del Andévalo Onubense y su origen norteafricano", Congreso Internacional el Estrecho de Gibraltar, (Ceuta, 1987), tomo II, Madrid, pp. 333-343.

(1993): "Un lote de cerámica islámica de Niebla", Arqueología Medieval, 2, Campo Arqueológico de Mértola, ed. Afrontamento, Porto, pp. 55-62.

PUERTAS TRICAS, Rafael (1986): “Cerámica islámica en verde y morado de la alcazaba de Málaga", Cuadernos de la Alhambra, 21-22, Granada, pp. 31-65.

(1989): La cerámica islámica de cuerda seca en la alcazaba de Málaga. Ayuntamiento de Málaga, Málaga.

REGO, Miguel Luis Vieira (1994): "Investigações arqueológicas no Castelo de Noudar", Arqueología en el entomo del Bajo Guadiana, Universidad de Huelva, Huelva, pp. 37-53.

RETUERCE VELASCO, Manuel (1984): "La cerámica islámica de Calatalifa. Apuntes sobre los grupos ceramicos de la Marca Media", Boletín del Museo Arqueológico Nacional, vol. II, n I, Madrid, pp. I 17-I36.

(1986): "Cerámica islámica de la "Cidade das Rosas" Serpa (Portugal)", II C.C.M.M.O., ed. Ministerio de Cultura, Madrid, pp. 85-92.

RETUERCE, M. e ZOZAYA, J. (1986): "Variantes geográficas de la cerámica omeya andalusí: los temas decorativos", II C.C.M.M.O., (Siena/Faenza, 1984), Firenze, pp. 69-128.

(199|): "Variantes y constantes en la cerámica andalusí", IV C.C.M.M.O., (Lisboa, 1987), ed. Campo Arqueológico de Mértola, pp. 315-322.
ROSSELLO BORDOY, Guillermo (1978): Ensayo de sistematización de la cerámica arabe en Mallorca. Palma de Mallorca.

(199|): El nombre de las cosas en Al-Andalus: una propuesta de terminología cerámica. Palma de Mallorca.

(1994): "Arqueología e información textual: el utillaje en la cocina andalusî", La alimentación en las culturas islámicas, Colección de Estudios Editados por Manuela Marín y David Waines, Agencia Española de Cooperación Internacional, Madrid, pp. 37-87.

SALVATIERRA CUENCA, Vicente e CASTILLO, J. C. (1993): "Las cerámicas precalifales de la Cora de Jaén", La cerámica altomedieval en el Sur de Al-Andalus, Primer Encuentro de Arqueología y Patrimonio, Granada, pp. 239-258.

SOLER, Alvaro e ZOZAYA, Juan (1989): "Castillos omeyas de planta cuadrada: su relación funcional", III C.A.M.E., Oviedo, pp. 265-274.

SOUTO, Juan A. (1994): "Obras construtivas en al-Andalus durante o emirato de Muhammad I segun el volumen II del Muqtabis de Ibn Hayyan", Trabalhos de Antropologia e Etnologia, vol. 34 (3-4), Porto, pp. 35I-360.

TEICHNER, Felix (1994): "Évora. Vorbericht über die ausgrabungen am römischen temple (1986-1992). Stratigraphische untersuchungen und aspekte der stradtgeschichte", Madrider Mitteilungen, 35, Madrid - Mainz, pp. 336-358.

TORRES, Cláudio (1987): Cerâmica islâmica portuguesa. Campo Arqueológico de Mértola, Mértola.

TORRES, Cláudio, PALMA, M. P. et al. (1991): "Cerâmica islâmica de Mértola - propostas de cronologia e funcionalidade", IV C.C.M.M.O., (Lisboa, 1987), ed. Campo Arqueológico de Mértola, pp. 497-536.

(1996): "Técnicas e utensilios de conservação dos alimentos na Mértola islâmica", Arqueologia Medieval, 4, Campo Arqueológico de Mértola, ed. Afrontamento, Porto, pp. 203-217.

VALDÉS FERNANDES, Fernando (1985): La Alcazaba de Badajoz - I. Hallazgos islámicos (1977-1982) y testar de la Puerta del Pilar. Ministerio de Cultura, Madrid.

VIANA, Abel (1959): "Notas históricas, arqueológicas e etnográficas do Baixo Alentejo - I. Castro de Nossa Senhora da Cola", A.B., vol. XVI, Beja, pp. 3-24.

(1960): "Notas históricas, arqueológicas e etnográficas do Baixo Alentejo", A.B., vol. XVII, Beja, pp. I38-23I.

ZOZAYA, Juan (1980a): "Aperçu general sur la céramique espagnole", I C.C.M.M.O., (Valbonne 1978), ed. CNRS, Paris, pp. 265-296. 
(1980b): "Essai de chronologie pour certains types de poteries califale andalouse", I C.C.M.M.O., (Valbonne 1978), ed. CNRS, Paris, pp. 3।I-3।5.
(1985): "Excavaciones en la fortaleza de Qa'at 'AbdAl-Salam (Alcalá de Henares, Madrid)", N.A.H., vol. 24, Ministerio de Cultura, Madrid, pp. 4I3-522.

\section{Siglas e Abreviaturas}

A.A.C. - Anales de Arqueología Cordobesa.

A.B. - Arquivo de Beja.

A.E.A. - Archivo Español de Arqueología. Madrid.

Arq.Port. - O Arqueólogo Português. Lisboa.

B.A.M. - Boletín de Arqueología Medieval. Madrid.

C.A.M.E. - Congreso de Arqueología Medieval Española.

CCV - Colección de la Casa Velazquez.

C.C.M.M.O. - Colóquios de Cerâmica Medieval no Mediterrâneo Ocidental.

C.S.I.C. - Consejo Superior de Investigaciones Científicas.

E.A.E. - Excavaciones Arqueológicas en España. Madrid.

I.N.S.A.P. - Institut National des Sciences de I'Archéologie et du Patrimoine. Rabat.

M.C.V. - Mélanges de la Casa de Velazquez. Paris.

N.A.H. - Noticiario Arqueológico Hispánico. Madrid. 


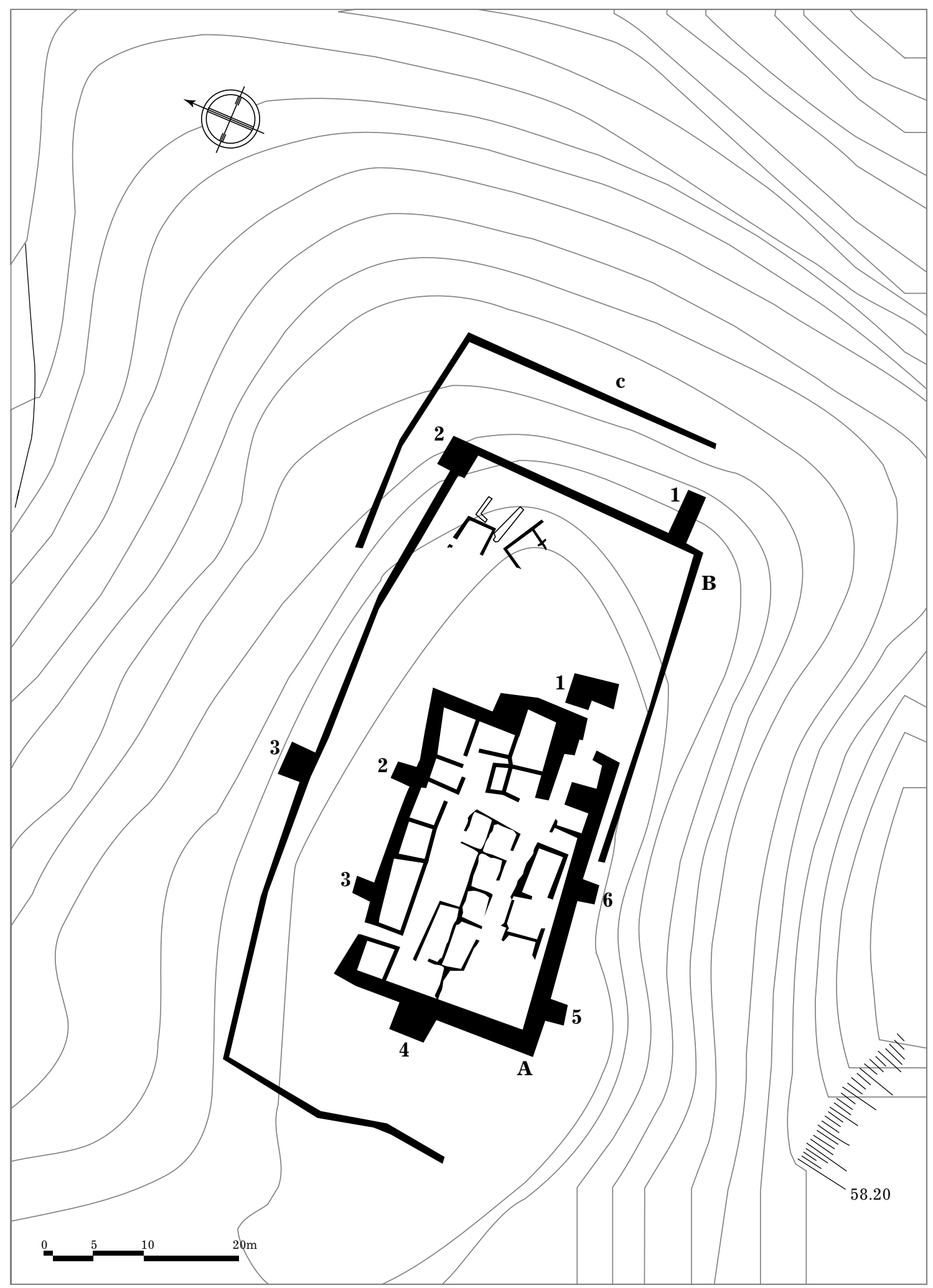

Fig. I. Planta topográfica parcial do Castelo Velho de Alcoutim, com indicação das estruturas habitacionais da última fase de ocupação 


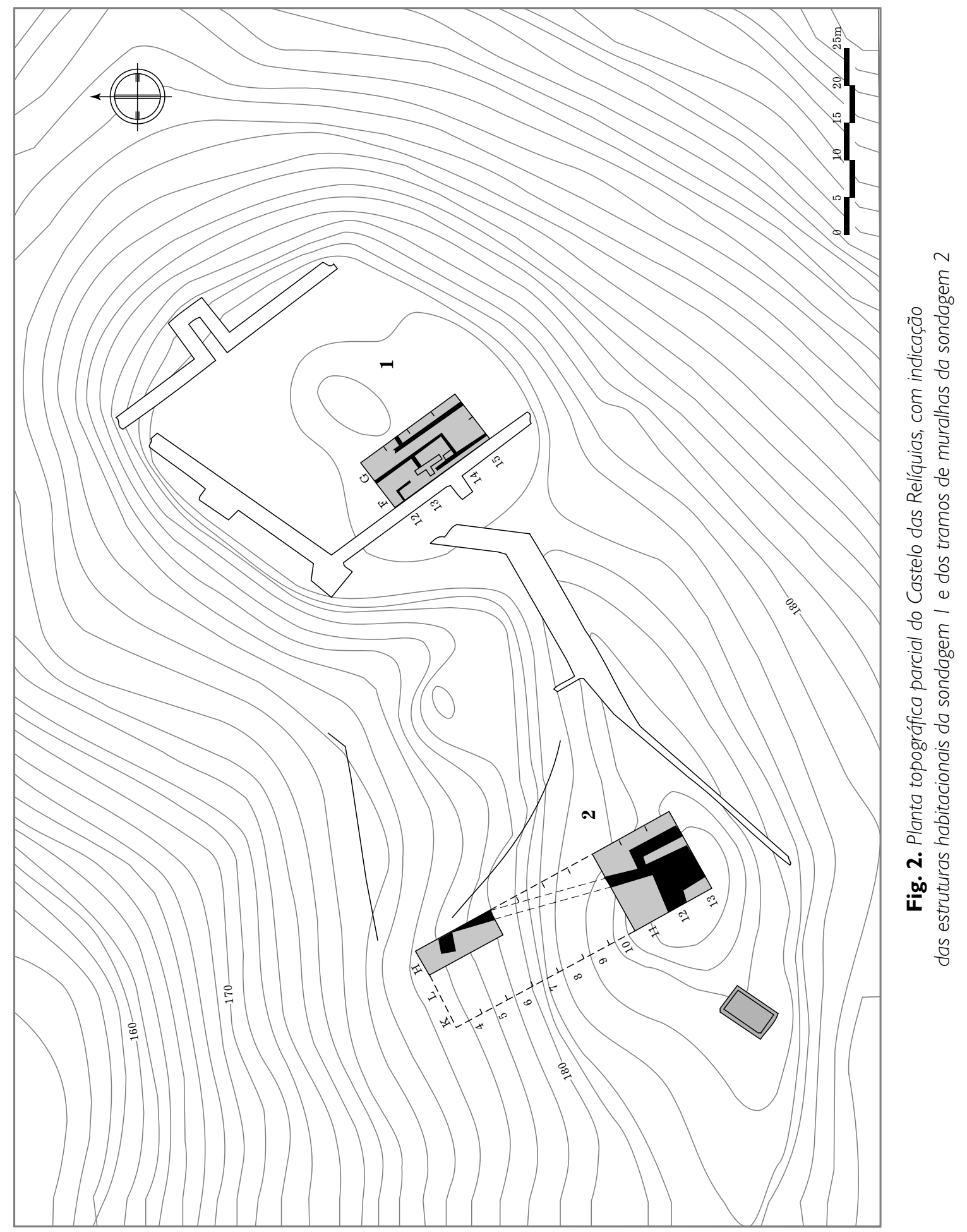



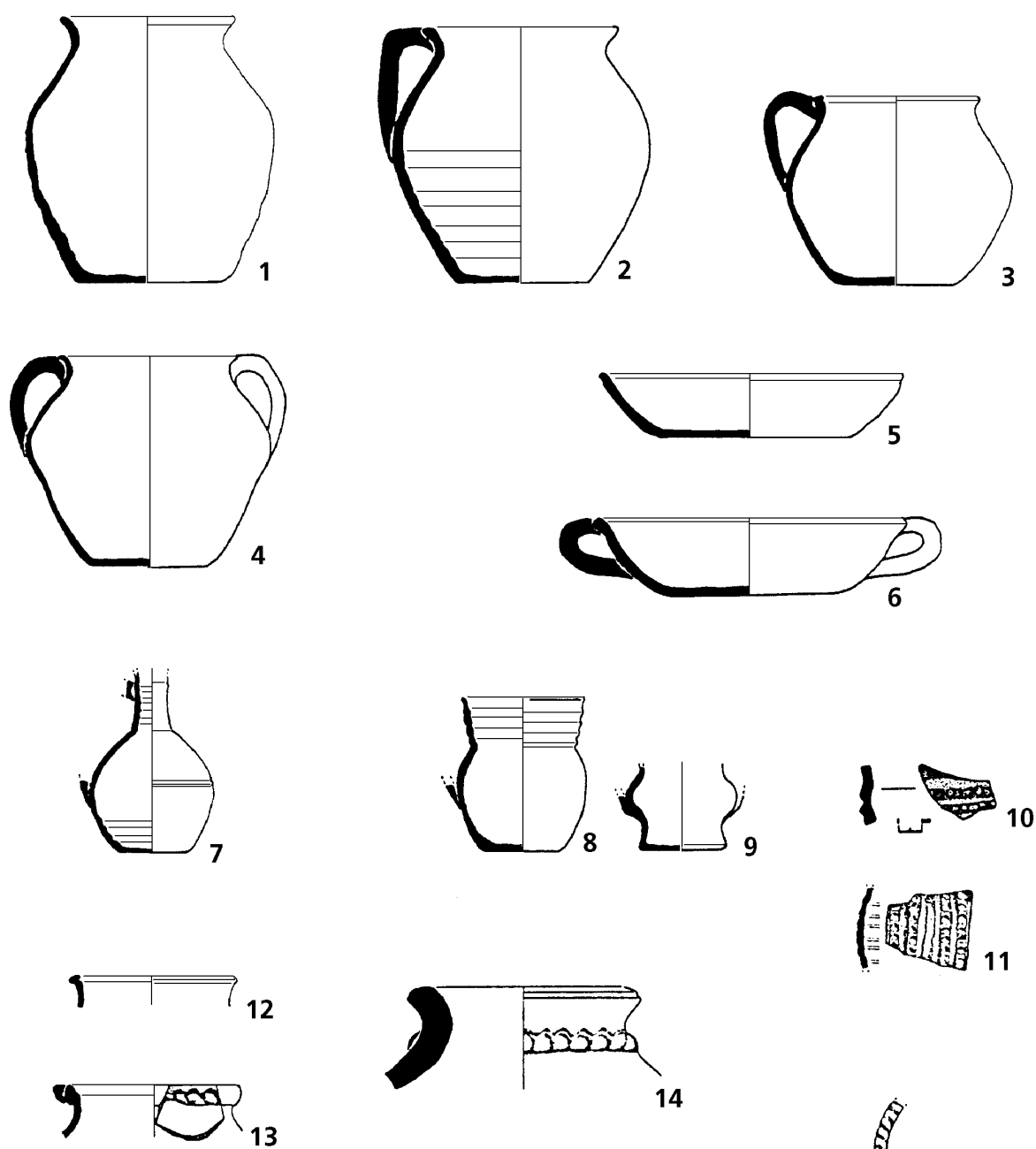

14
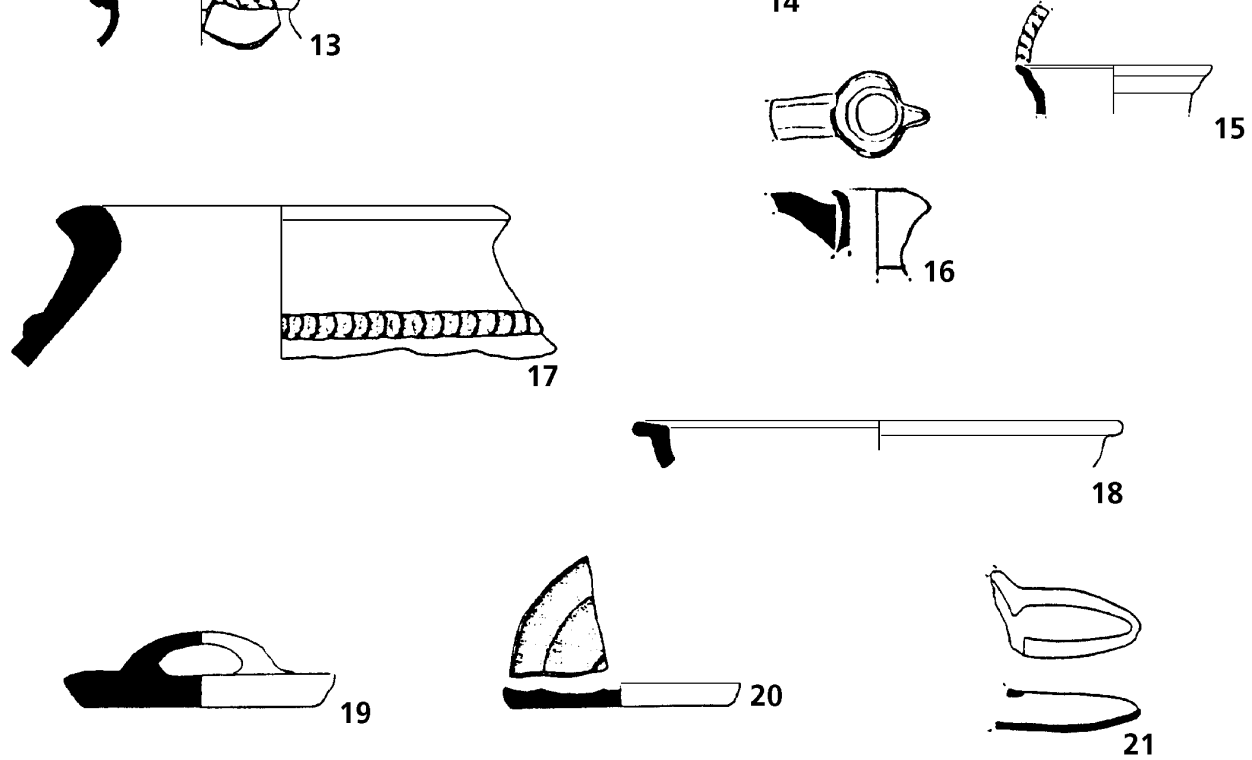

Est. I. Cerâmicas recolhidas nos níveis da $1^{a}$ fase de ocupação: Castelo Velho de Alcoutim ( $n^{\circ}$ 1, 2, 3, 11, 12, 13, 14, 15, 16, 17, 21) Castelo das Relíquias ( $\left.n^{\circ} 4,5,6,7,8,9,10,18,19,20\right)$ 

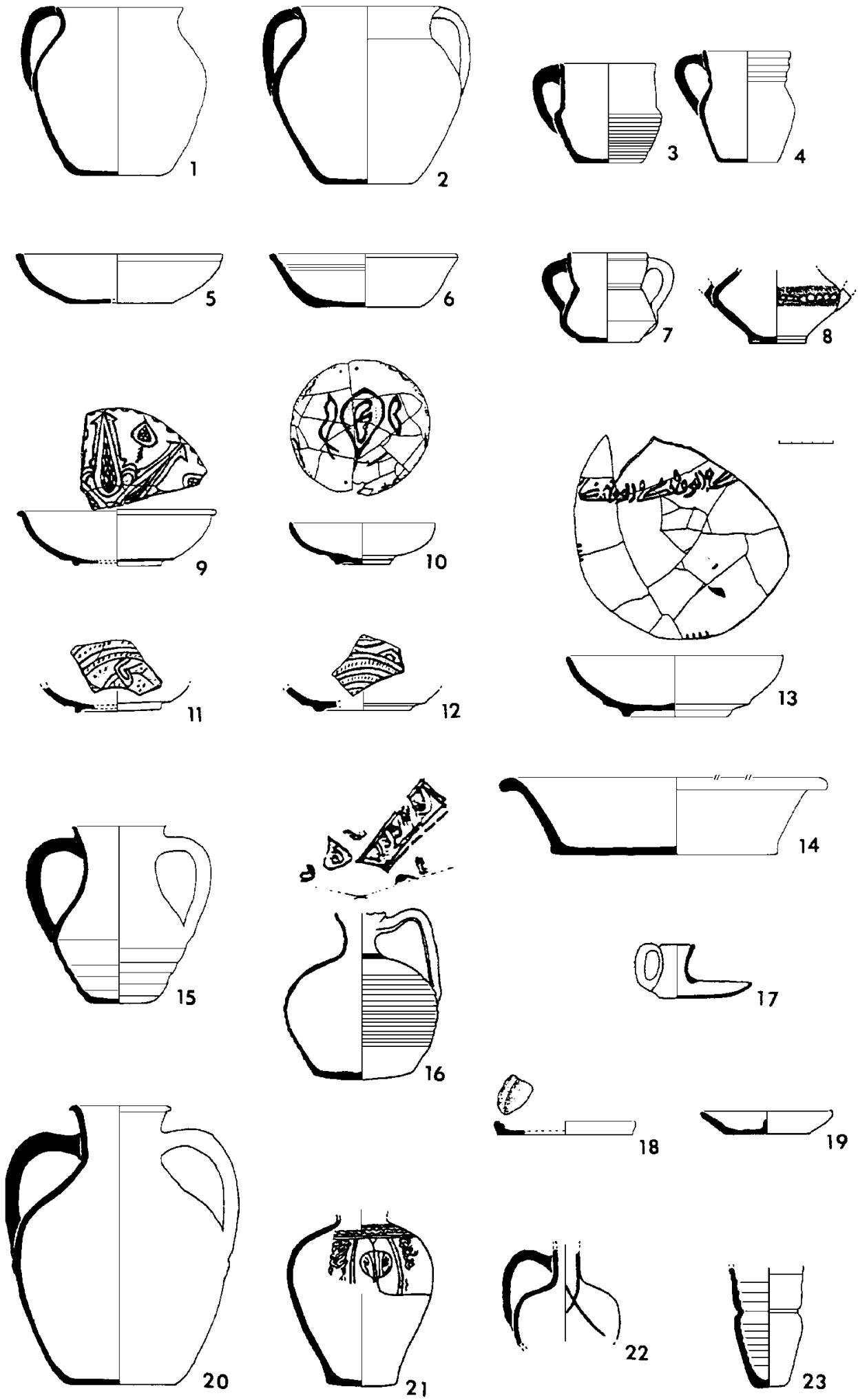

Est. II. Cerâmicas recolhidas nos níveis da $2^{a}$ fase de ocupação:

Castelo Velho de Alcoutim ( $n^{\circ}$ I, 2, 3, 4, 5, 6, 7, 9, 10, 11, 12, 13, 14, 15, 16, 17, 20, 23) Castelo das Relíquias (n०8, 18, 19, 21, 22) 

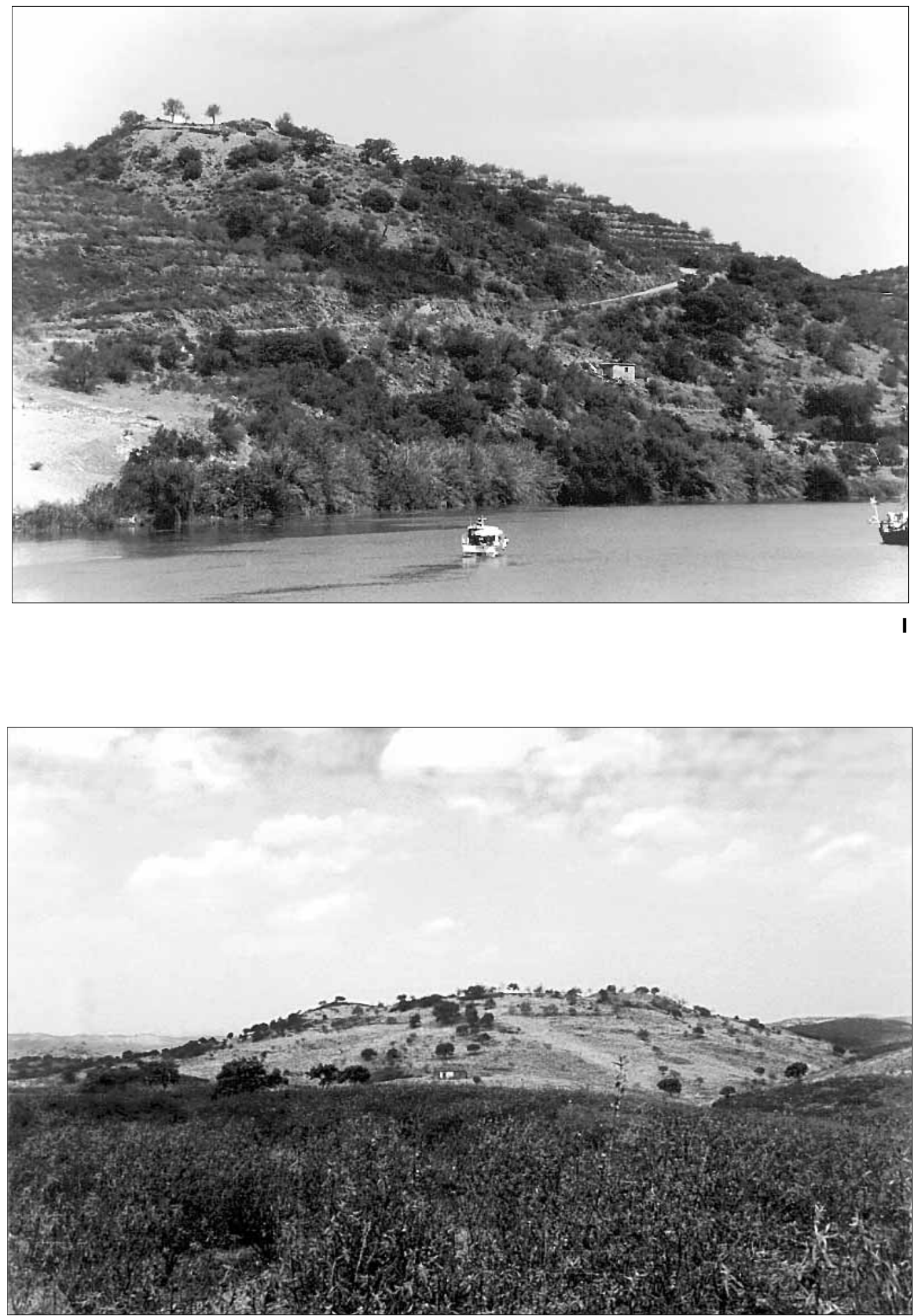

Est. III. I. Cerro do Castelo Velho de Alcoutim visto de sudeste a partir de San Lúcar del Guadiana

2. Cerro do Castelo das Relíquias, visto de sul 

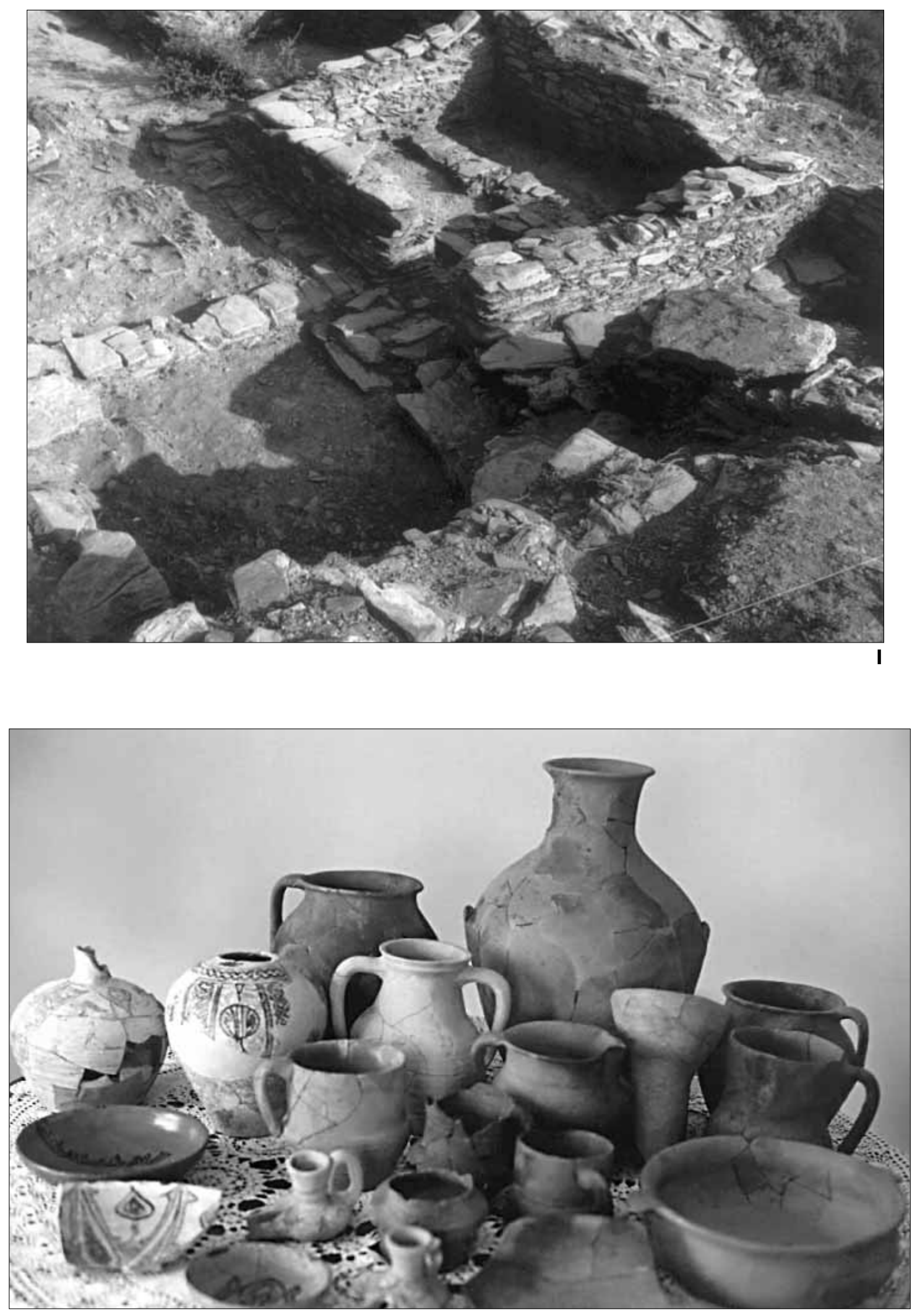

Est. IV. I. Pormenor das escavações no Castelo Velho de Alcoutim, vendo-se estruturas habitacionais da $1^{a}$ e da $2^{a}$ fase de ocupação

2. Conjunto de cerâmicas omíadas do Castelo Velho de Alcoutim e Castelo das Relíquias 